\title{
Functionalized Materials as a Versatile Platform for Enzyme Immobilization in Wastewater Treatment
}

\author{
Agnieszka Kołodziejczak-Radzimska ${ }^{1}$ (D) $\cdot$ Long D. Nghiem ${ }^{2,3}$ (D) $\cdot$ Teofil Jesionowski $^{1}$ (D)
}

Accepted: 17 May 2021 / Published online: 1 June 2021

(C) The Author(s) 2021

\begin{abstract}
Purpose of Review Untreated wastewater discharge can significantly and negatively impact the state of the environment. Rapid industrialization and economic development have directly contributed to land and water pollution resulting from the application of many chemicals such as organic dyes, pharmaceuticals, and industrial reagents. The removal of these chemicals before effluent discharge is crucial for environmental protection. This review aims to explore the importance of functionalized materials in the preparation of biocatalytic systems and consider their application in eliminating water pollutants.

Recent Findings Wastewater treatment methods can be classified into three groups: (i) chemical (e.g., chemical oxidation and ozonation), (ii) physical (e.g., membrane separation and ion exchange), and (iii) biological processes. Biological treatment is the most widely used method due to its cost-effectiveness and eco-friendliness. In particular, the use of immobilized enzymes has recently become more attractive as a result of scientific progress in advanced material synthesis. The selection of an appropriate support plays an important role in the preparation of such biologically active systems. Recent studies have demonstrated the use of various materials for enzyme immobilization in the purification of water.

Summary This review identifies and discusses different biocatalytic systems used in the enzymatic degradation of various water pollutants. Materials functionalized by specific groups can serve as good support matrices for enzyme immobilization, providing chemical and thermal stability to support catalytic reactions. Enzymatic biocatalysis converts the pollutants into simpler products, which are usually less toxic than their parents. Due to immobilization, the enzyme can be used over multiple cycles to reduce the cost of wastewater treatment. Future studies in this field should focus on developing new platforms for enzyme immobilization in order to improve degradation efficiency.
\end{abstract}

Keywords Enzyme immobilization · Functionalized materials $\cdot$ Biodegradation $\cdot$ Organic pollutants $\cdot$ Wastewater treatment

This article is part of the Topical Collection on Water Pollution

Agnieszka Kołodziejczak-Radzimska

Agnieszka.Kolodziejczak-Radzimska@put.poznan.pl

$\triangle$ Teofil Jesionowski

Teofil.Jesionowski@put.poznan.pl

1 Institute of Technology and Chemical Engineering, Faculty of Chemical Technology, Poznan University of Technology,

Berdychowo 4, PL-60965 Poznan, Poland

2 Centre for Technology in Water and Wastewater, School of Civil and Environmental Engineering, University of Technology Sydney, Sydney, Australia

3 Institute of Environmental Sciences, Nguyen Tat Thanh University, Ho Chi Minh City, Viet Nam

\section{Introduction}

Functionalized materials in organic, inorganic, hybrid, and composite forms can be modified to have desirable properties for industrial application. Amongst these properties, particle size and size distribution, shape and purity, and crystallographic and porous structure play important roles for surface functionalization $[1 \bullet \cdot, 2,3]$. Through functionalization, it is possible to introduce organic and inorganic moieties into these materials [4]. Functionalized materials have been widely used in many industries such as the food processing (e.g., beer and wine production, nutritive and nonnutritive food additives, and food protection), pharmaceutical (e.g., drug delivery and drug synthesis), cosmetics (fragrance, film formers, and cosmetic ingredients), electronics (molecular electronics, organic photovoltaics, and biosensors), and textile (in the production of antimicrobial, self-cleaning, temperature regulating, 
moisture-wicking, flame-retardant, and self-healing textiles) industries $[5,6]$. Enzyme immobilization is an important research topic in the application of functionalized materials to improve performance and potentially reduce the cost of enzymatic treatment. Considering the multifunctionality of the above-mentioned materials, this review describes their use in the process of enzyme immobilization.

A natural enzyme is usually only stable within a narrow $\mathrm{pH}$ and temperature range due to the water solubility of free enzymes. They can be hydrolyzed over time. Furthermore, water soluble enzymes are difficult to isolate from the reaction medium. Hence, the cost of enzymatic treatment can be very high [7•]. Enzyme immobilization is an effective strategy to overcome the disadvantages of a free enzyme system. Enzyme immobilization can be defined as the localization or closing of an enzyme in a defined region of space [8] to obtain a stable biocatalytic system. The immobilization of an enzyme on the surface of a specified material can improve its $\mathrm{pH}$, thermal, and storage stability. As a significant advantage, after immobilization, the enzyme is in a heterogeneous form and can be easily separated from the reaction medium for reuse [9-11]. From this perspective, the review focuses on the immobilization of enzymes on a selected group of materials (functionalized materials) and on their application in environmental remediation.

A wide variety of materials can be used as support matrices for enzyme immobilization. Their properties are of significant importance in determining the interaction between the enzyme and the support. The selection of an appropriate matrix also depends on the properties of the enzyme and the immobilization method [12-14]. A high surface area, porosity, hydrophilicity, biocompatibility, stability in reaction conditions, and availability at low cost are the most desirable properties of a support material [15-18]. Many of these benefits can be achieved using functionalized materials.

There have been several reviews on the role of immobilized enzymes in environmental applications, describing various types of biocatalytic systems based on oxidoreductases (laccase and peroxidase) and their use as catalysts in wastewater treatment. Some of them concern immobilized laccases $[19,20 \cdot, 21]$ and peroxidases $[22-24]$ and their potential application to remediate pollutants. Others refer to methods of immobilization, the support matrices used, and the types of pollutants treated $[8,25-27]$. In contrast to previous studies, this review will mainly focus on studies of oxidoreductases immobilized on functionalized materials (modified inorganic, organic compounds, and hybrids or composites) and the subsequent use of such systems in water purification processes (especially in the treatment of organic dyes, pharmaceuticals, phenol compounds, and polycyclic aromatic hydrocarbons).

\section{Functionalized Materials as Supports for Enzymes}

A diverse range of materials (e.g., natural, synthetic, inorganic, organic, and composite or hybrid) can be used for enzyme immobilization. Firstly, surface modification is conducted to improve the properties of these materials for a specific application. Different types of compounds are considered for this purpose, depending on the field of use. One key aspect of functionalization is the introduction of various types of functional groups to the material surface. Metal oxides (oxide systems), polymers (including biopolymers), and hybrids or composites can all serve as the base for functionalized materials, and many compounds are used to modify their surface $[2,6]$. Amino, carboxylic, hydroxyl, and sulfhydryl groups are commonly introduced. The modification process is of great importance when a material is intended for use as a support for enzyme immobilization. In some cases, support materials are inert and require activation. Functionalization allows the formation of stable covalent bonds between the functional groups found in the enzyme and the functional groups on the surface of the support material $[4,8]$.

Enzymes on the surface of functionalized materials can be immobilized by both physical (adsorption and entrapment) and chemical (covalent and cross-linking) methods. This is related to the physicochemical properties, the structure of the material, and the types of functional groups introduced to their surface. Physical immobilization is an attractive method because it does not change the conformation of the enzyme. Additionally, many functionalized materials have a large surface area allowing enzyme adsorption. The adsorption method is also simple and enables mobility of the enzyme. Conversely, chemical immobilization contributes to a high catalytic efficiency, stability, and a low mass transfer resistance of the immobilized enzyme. In the chemical method, a reaction occurs between the amino groups on the protein surface and the functional groups (e.g., carboxylic, epoxy, thiol) on the functionalized materials [28]. Figure 1 provides an overview of the functionalized materials, active functional groups for enzyme immobilization, immobilizing mechanisms, and the water pollutants that can be removed by an immobilized enzymatic system.

Inorganic materials, both natural and synthetic (oxides, zeolites, silicates, active carbons, etc.), are commonly used in immobilization processes. These substances are characterized by high resistance, stability, and availability. Moreover, their synthesis can proceed via simple and fast methods, making them relatively cheap. The high value of these materials as carriers in protein immobilization results from their defined porous structure and significant sorption capacity. It should also be noted that on the surface of the most commonly used inorganic materials (inorganic oxides), specific chemical groups can be introduced to increase their affinity to enzymes. 


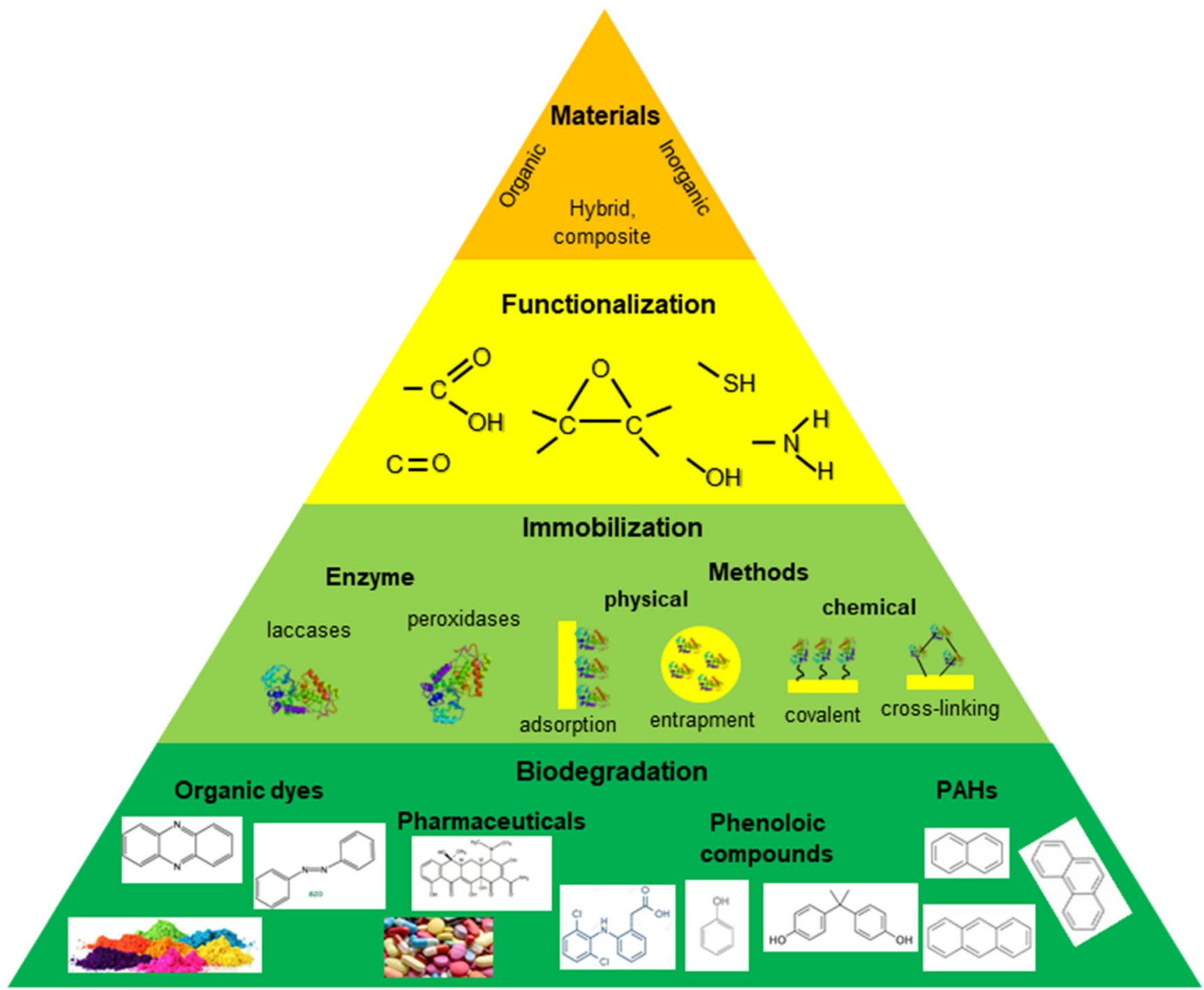

Fig. 1 Overview of preparation of biocatalytic systems and their application in pollutant degradation

This is especially important in the case of immobilization with the formation of covalent bonds. The high activity of the immobilized enzyme prevents any diffusion resistance in the transport of the components of the reaction mixture and enables the use of the immobilized system over several reaction cycles [12].

Polymers are another large group of organic materials utilized in enzyme immobilization. These materials can be obtained from natural sources (biopolymers) or synthesized with high precision in laboratory conditions. The properties and enzymatic capacity of synthetic polymers can be adjusted to the specific enzyme and the intended application. The polymeric matrix can be functionalized by building monomers into its structure. The monomers contain functional groups capable of forming chemical bonds with the enzyme moieties. Besides, synthetic polymers are characterized by high thermal and mechanical stability. These materials can act as supports for enzymes from various catalytic groups with applicability in many industrial processes. Biopolymers are omnipresent.
They have a high affinity to enzymes, offer biocompatibility, and do not cause toxicity of the enzyme [29]. Many of them are chemically resistant and stable under the conditions of catalyzed reactions. The greatest advantage of biopolymers is the presence of many groups in their structure which are responsible for binding with the enzymes or enabling the effective modification of their surface [13].

Apart from inorganic and organic substrates, hybrids and composites also constitute an interesting group of materials for enzyme immobilization, including such systems as inorganicinorganic (different oxide systems, e.g., $\mathrm{SiO}_{2} / \mathrm{MgO}$ and $\mathrm{ZrO}_{2} /$ $\mathrm{SiO}_{2}$ ), organic-organic (e.g., chitosan/alginate and polyvinyl alcohol/chitosan), and inorganic-organic $\left(\mathrm{SiO}_{2} /\right.$ chitosan and $\mathrm{Fe}_{3} \mathrm{O}_{4}$ /polyethyleneimine). The properties of these materials can be precisely designed for the specific enzyme and the target application. Additionally, they combine the properties of both precursors, increasing the resulting functionality and extending the range of applicability [26]. 


\section{Applications of Immobilized Enzymes for Removing Water Pollutants}

Many countries around the world have set targets for sustainable socioeconomic development with a focus on minimizing pollution. Highly efficient neutralization technologies are used to detect and degrade pollutants. Adsorption on active materials, chemical oxidation, ozonation, ultrafiltration, nanofiltration, and ion exchange are commonly used to purify wastewater. These technologies require significant energy consumption and are also characterized by low efficiency and stability, high cost, and the formation of harmful by-products $[19,30,31]$. Biological methods are an alternative for treating industrial wastewaters due to their availability, cost-effectiveness, and eco-friendliness. These methods are based on three main processes: biosorption, bioaccumulation, and biodegradation, or a combination of these. Regarding biodegradation, an enzyme participates in the conversion of the pollutants to simpler compounds usually with less toxicity than the initial ones $[21,32,33]$. The use of native enzymes to degrade pollutants is subject to certain limitations, such as low stability and difficulty of recovery, which impair their reusability. For this reason, immobilized enzymes are often utilized in the degradation of wastewaters. During immobilization, the structure is stabilized, while the thermal and $\mathrm{pH}$ stability and repeatability are improved; it may thus become a good candidate for industrial application [25, 34].

This review highlights systems containing laccase and peroxidase immobilized on functionalized materials and their application to remove organic dyes, pharmaceuticals, and phenol compounds from wastewaters. A subsequent part of the review provides examples of industrial applications of immobilized enzymes.

\section{Organic Dyes}

Organic dyes are widely used in the textile industry. Water pollution by organic dyes is a significant and challenging environmental problem. Some organic dyes are toxic and persistent in the environment. They also discolor bodies of water giving them an unpleasant visual appearance. Despite the low content of dyes in wastewater, the color is a characteristic indicator of their presence. The decolorization and degradation of organic dyes can be effectively achieved with immobilized enzymes.

Previous studies have confirmed the effectiveness of oxidoreductases in the degradation of dyes. Laccases are most commonly used enzyme for this wastewater treatment application [35-37]. The immobilization of these enzymes mainly focuses on silica and its composites [38, 39]. Lopez-Barbosa et al. [40] performed experiments with laccase immobilized on functionalized silica for decolorizing Congo Red. The silica was modified with APTES ( $\gamma$-aminopropyltriethoxysilane), and the $\mathrm{NH}_{2}$ groups were subsequently activated by adding glutaraldehyde (GA). Afterward, the laccase was conjugated by formatting the imine bonds. The laccase/silanized silica was introduced into textile filters to extend the activity of the enzyme molecules when incorporated in a continuous remediation process. Functionalized silica was also used by Salami et al. to prepare a biocatalyst [41]. In this case, the silica was modified with 3glycidyloxypropyltrimethoxysilane (3-GPTMS). The laccase/ epoxy-functionalized silica was used for the decolorization of five dyes (Acid Orange 156, Acid Red 52, Coomassie Brilliant Blue, Methyl Violet, and Malachite Green). The proposed biocatalyst demonstrated good stability in terms of temperature, $\mathrm{pH}$, and organic solvents. The results showed a correlation between the dye structure and the decolorization rate [41].

Functionalized $\mathrm{Fe}_{3} \mathrm{O}_{4}$-based materials are another large group of compounds used as carriers for laccase [42-45]. For example, Liu et al. [46] synthesized a magnetic poly ( $p$ phenylenediamine) nanocomposite $\left(\mathrm{P} p \mathrm{PD} / \mathrm{Fe}_{3} \mathrm{O}_{4}\right)$. Laccase was then immobilized on the $\mathrm{P} p \mathrm{PD} / \mathrm{Fe}_{3} \mathrm{O}_{4}$ system and used as a catalyst to remove Reactive Blue 19 dye. The proposed biocatalytic system $\left(\mathrm{Lac} / \mathrm{P} p \mathrm{PD} / \mathrm{Fe}_{3} \mathrm{O}_{4}\right)$ exhibited high stability, easy recovery, reuse capabilities, and high removal efficiency for Reactive Blue 19 dye. $\mathrm{Fe}_{3} \mathrm{O}_{4}$ functionalized with amino groups was employed by Gao et al. to support laccase [47]. The results confirmed the effective decolorization of Acid Fuchsin using the obtained biocatalysts (laccase/aminofunctionalized $\mathrm{Fe}_{3} \mathrm{O}_{4}$ ). In another interesting study by Ulu et al. [48], laccase was immobilized on iron oxide modified with thiolated chitosan (TCS). The results showed the longterm activity of the system in the decolorization of two dyes (Reactive Blue 171 and Acid Blue 74).

Titanium dioxide-based photocatalysis is useful because of its low cost, non-toxicity, high photocatalytic activity, and stability. However, degradation by photocatalysis is only adequate for wastewater with low concentrations of dye. In this case, the aqueous solution should be transparent to allow light penetration [49]. Khakshoor et al. [50] described a two-step decolorization by co-entrapped spore laccase and $\mathrm{TiO}_{2}$ nanoparticles. The first stage of this process involved the pretreatment of the dye with laccase in dark conditions. This was followed by treatment with $\mathrm{TiO}_{2}$ (photocatalysis under UV radiation). Titania modified with glycidylacrylate (GA) [51・•] and titanium(IV) bis(ammonium lactato)dihydroxide (Ti-BALDH) [52] were also employed as laccase supports and applied in the degradation of different organic dyes (Rhodamine B and Malachite Green). The results showed that a biocatalytic system based on titania and laccase can be successfully utilized to remediate organic pollutants.

Natural and synthetic polymers are attractive materials as enzyme supports. The functionalization of their surface enables their multifunctional application for enzyme 
immobilization and wastewater treatment [53]. Gioia et al. [54] described the immobilization of laccase on thiolsulfinate-agarose and the ability of the system to degrade azo dyes. Chitosan is another biopolymer commonly used for enzyme immobilization. The practical operability and efficiency of immobilization on chitosan are improved by incorporating certain inorganic materials such as clays. A catalyst based on functionalized chitosan and laccase can be successfully used for dye treatment [55]. Synthetic polymers, especially their modified forms, are frequently employed as enzyme carriers. In the literature, poly(methyl methacrylate)/ polyaniline electrospun fibers [56] and a polydopaminecoated poly(vinylidene fluoride) membrane (PDA@PVDF) [57] have also been used to immobilize laccase and subsequently used in the removal of organic dyes from wastewaters.

Peroxidases are another group of enzymes that can catalyze oxidation reactions. Peroxidases immobilized on various kinds of supports have been successfully utilized for the decolorization and detoxification of waste dyes [23, 58-60]. Many researchers have also used horseradish peroxide (HRP) in the degradation of organic dyes. For example, Sun et al. [61] researched the immobilization of horseradish peroxidase on silica coated with zinc oxide. The results indicated that the proposed catalyst $\mathrm{HRP} / \mathrm{ZnO} / \mathrm{SiO}_{2}$ exhibited a high decolorization efficiency and good reusability for anthraquinone dyes. The same enzyme (HRP) was immobilized on a functionalized hybrid system (graphene oxide-silica). The surface of this material was modified with APTS (3aminopropyltriethoxysilane) [62•]. The authors reported that the prepared biocatalytic system achieved $100 \%$ efficiency in the decolorization of dyes. In many cases, horseradish peroxidase or other enzymes are co-immobilized with chloroperoxidase (CPO) and immobilized on various supports $[63,64]$. A noteworthy study is that of Cheng et al. [65], who proposed a polydopamine-tethered $\mathrm{CPO} / \mathrm{HRP}-\mathrm{TiO}_{2}$ nanocomposite as an enzyme-photo bifunctional synergistic catalyst in water treatment. In this case, the $\mathrm{TiO}_{2}$ played the roles of both a solid and a photocatalyst in the decolorization of organic dyes. Furthermore, Kiran et al. [57] immobilized lignin peroxidase on functionalized $\mathrm{MnFe}_{2} \mathrm{O}_{4}$ and utilized it to decolorize dyes. Graphene oxide was employed for modification, changing the surface properties of $\mathrm{MnFe}_{2} \mathrm{O}_{4}$ to make them more hydrophilic for the binding of biomolecules.

In summary, functionalized materials play an important role in the immobilization of enzymes. The selection of an appropriate modifier makes it possible to change the character of the carrier surface in a way that increases the efficiency of the immobilization process. Additionally, in this case, the bonds between the enzyme and support are more stable, which is important when the discussed system is used repeatedly for industrial applications. The examples presented above indicate that biocatalytic systems based on functionalized materials can effectively decolorize and degrade toxic dyes in a water environment. Moreover, the research shows that purified solutions (both model and real) are less toxic after degradation using functionalized material/enzyme systems compared with the solutions before degradation.

\section{Pharmaceutically Active Compounds}

Pharmaceutical pollution has become an increasingly serious problem due to the increased consumption of pharmaceuticals and growth of the pharmaceutical industry. In addition, the prevalence of chronic diseases, the development of science and technology, and the growing world population have contributed to the increasing presence of pharmaceutically active compounds in the aquatic environment [66••, 67]. These pollutants are discharged by various antibiotics and medicines, including those available without prescription [68, 69]. As in in the case of dyes, pharmaceutical pollutants can be degraded by biological methods (especially using immobilized oxidoreductases) into simpler and safer derivatives [70, 71].

One pharmaceutical frequently used to evaluate the efficiency of enzymatic treatment is diclofenac, which is a nonsteroidal anti-inflammatory drug. In water, diclofenac causes genetic and systemic damage to various living organisms [70, 72]. Xu et al. [73] employed functionalized carbon nanotubes as the support matrix for laccase to prepare a polyvinyl alcohol (PVA)/chitosan (CS)/multi-walled carbon nanotubes (MWNTs) composite nanofibrous membrane. It was reported that after immobilization on PVA/CS/MWNTs, the laccase retained high activity and demonstrated a high rate of removal of diclofenac from the wastewater. A study by Teheran et al. [74] presented biochar activated by polyacrylonitrile (PAN) and entrapped in nanofibers by an electrospinning method. This process provided adsorption capability in the membrane and increased the contact time between the immobilized laccase and the pharmaceutical pollutants. Experiments using biochar as a carrier for laccase in order to biodegrade diclofenac were also performed by Lionappan et al. [75]. In this report, the biochar was modified with citric acid, which allowed the introduction of carbonyl groups to the biochar surface. This increased the reaction between the enzyme and the support. Diclofenac was also biotransformed with great efficiency by laccase immobilized on amino-functionalized $\mathrm{TiO}_{2}$ [76]. The biocatalyst presented by Garcia-Morales et al. is a good alternative for removing pharmaceutical compounds from water environments. Immobilized laccase was also used to transform or degrade diclofenac from industrial effluents in a study by Neelkant et al. [77]. A polyvinyl alginate-silicon dioxide matrix was utilized. Liquid chromatography-mass spectrometry (LC-MS) analysis showed that diclofenac was transformed through a ringopening reaction and mineralization after hydroxylation.

Tetracycline (TC) and carbamazepine (CBZ) are other pharmaceutical compounds that have also been used to 
demonstrate the efficiency of immobilized enzymes. A wide range of sexually transmitted diseases, as well as gastritis, peptic ulcers, and lower respiratory tract infections, are treated with tetracycline and its derivatives. In turn, carbamazepine is used as an anticonvulsant and mood-stabilizing drug to treat epilepsy and bipolar disorder. Interesting research concerning the removal of tetracycline was conducted by Teheran et al. [78]. Laccase was immobilized on a polyacrylonitrile-biochar composite nanofibrous membrane. The resulting biocatalytic system, used in continuous mode, achieved a chlortetracycline removal efficiency of around $50 \%$. The same pharmaceutical compound was biodegraded by Garcia-Delgado et al. [79०0]. In this case, aminofunctionalized stevensite and biochar were employed to immobilize laccase. The results showed that the immobilized laccase system could degrade $100 \%$ of the tetracycline. In other studies, carbamazepine was removed from wastewater by laccase immobilized on oxygen-functionalized nanobiochars [80] and polyimide aerogels [81]. The nanobiochar was treated with acid, thus introducing carboxylic groups to the surface, which led to the greatest immobilization efficiency. At the same time, a high degradation of CBZ was achieved. Similar results were obtained with laccase immobilized on polyimide aerogels.

Based on the above-mentioned reports, it may be concluded that enzymes immobilized on functionalized materials can be used successfully to degrade pharmaceutical pollutants. Different types of materials functionalized by various compounds are used as supports for oxidoreductase immobilization. The results presented demonstrate the great efficiency of biocatalytic systems based on these materials in the degradation of pharmaceutical pollutants. Oxidoreductases supported on functionalized materials exhibit higher activity and better performance in the removal of pharmaceutical compounds. Moreover, they enable the reusability of the supported enzyme over several degradation cycles and can lead to a lower toxicity of the solutions after treatment.

\section{Phenol Compounds and Polycyclic Aromatic Hydrocarbons}

Expanding industrial activity can lead to an increased occurrence of toxic chemicals such as phenolic compounds in wastewater. These compounds may derive from the metallurgic, petrochemical, and pharmaceutical industries and organic chemical synthesis. Phenolic compounds pose an enormous hazard to organisms and the environment and should therefore be quickly removed. Enzymatic methods are commonly used to degrade these industrial chemicals $[82,83]$.

Horseradish peroxidase (HRP) and laccase (Lac) are effective enzymes for converting phenolic compounds in aqueous solutions to polymeric phenolic aggregates [83]. They have been immobilized on different functionalized inorganic oxides to improve their stability in the degradation of phenolic compounds.
Silica and its functionalized forms have also been used as support matrices for immobilizing enzymes in order to remove phenolic pollutants. Vishu et al. [84] reported a biocatalytic system consisting of a co-immobilized lignolytic enzyme cascade on multifunctionalized magnetic silica microspheres (MSMS). A facile method for the co-immobilization of laccase and peroxidase on MSMS was evaluated, the optimization of the operational parameters was carried out, and the reaction kinetics were determined. The prepared biocatalyst was used in the transformation of phenolic contaminants in the wastewater from a biorefinery. The results demonstrated the effective removal of different classes of phenolic compounds (phenol, chloro-, trichloro- and dichlorophenol, cresols, dimethyl-, 2-methyl-4,6-dinitro-, 4-nitro-, tetrachloroand pentachlorophenol). Silica-based material was also been studied by Mohammadi et al. [85]. In this case, the silica was modified with epoxy groups, and the laccase was covalently immobilized using nucleophilic attack by the amino groups of the laccase on the epoxy groups of the support. The performance of the biocatalytic system was evaluated in the removal of phenolic constituents, including phenol, $p$-chlorophenol, and catechol. The degradation of the catechol was highly efficient (about 95\%). A nanocomposite based on reduced graphene oxide (GO) and silica was also used to immobilize HRP [86]. GO and its reduced form (RGO), due to the presence of carboxylic, hydroxyl, and epoxide groups on the surface, are suitable matrices for enzyme immobilization. Moreover, composites with RGO and silica offer good surface area, surface roughness, and functionalization. Vineh et al. [86] evaluated the kinetic parameters, reusability, and stability of the enzyme for catalytic activity. Additionally, the obtained biocatalyst $\left(\mathrm{GO} / \mathrm{SiO}_{2} / \mathrm{HRP}\right)$ was utilized in the removal of high concentrations of phenol compounds from the water solution. The same research group also reported results concerning the immobilization of HRP on aminofunctionalized RGO which confirmed the conclusions from the previous study [87॰].

Many materials based on $\mathrm{Fe}_{3} \mathrm{O}_{4}$ are applied in the immobilization of enzymes because of their unique properties. Due to its ferromagnetic features, the magnetite support allows the prepared biocatalytic system to be easily recovered from the reaction [15]. The literature shows that $\mathrm{Fe}_{3} \mathrm{O}_{4}$ can be modified with biopolymers, polymers, and functional groups. Chitosan was used by Zhang et al. [88] to coat $\mathrm{Fe}_{3} \mathrm{O}_{4}$ nanoparticles. Furthermore, the product was used as a support for laccase immobilization, and the resulting biocatalysts were highly efficient in the degradation of the chlorophenol in the water solution. Interesting studies were also reported by $\mathrm{Wu}$ et al. [89], who modified $\mathrm{Fe}_{3} \mathrm{O}_{4}$ with amino groups. Then laccase was covalently adsorbed onto the amino-functionalized $\mathrm{Fe}_{3} \mathrm{O}_{4}$ and used to remove the phenolic compounds, achieving approximately $85 \%$ efficiency. After the reaction, the biocatalytic system was separated from the solution using a magnet. 
Other papers report on composites or hybrids containing magnetite particles. For example, $\mathrm{Fe}_{3} \mathrm{O}_{4}$ was coated with $\mathrm{MoS}_{2}$ during a synthesis process and then modified with polyethyleneimine, which created an electrostatic interaction between the core shell composite (like $\mathrm{Fe}_{3} \mathrm{O}_{4} @ \mathrm{MoS}_{2}$ ) and laccase and improved the dispersion of the magnetic nanoparticles [90]. In this way the efficiency of the laccase immobilization increased. Moreover, the biocatalytic system constructed was used in the degradation of persistent organic pollutants (e.g., bisphenol) in a water environment. Significant investigations involving the biodegradation of phenol were reported by Zhang et al. [24] and $\mathrm{Li}$ et al. [91]. They used $\mathrm{Fe}_{3} \mathrm{O}_{4}$-based composites with carbon nanotubes and nanodiamond, respectively, upon which horseradish peroxidase was immobilized. In both cases, the degradation of the phenol was highly efficient.

Polymers and biopolymers represent interesting groups of materials that are utilized as supports for oxidoreductase immobilization. In recent studies, polymers have been functionalized or linked with other compounds to improve their properties before immobilization is performed. In the research by Mohamed et al. [92], an acrylic fiber polymer was employed as a matrix for HRP. Before the immobilization process, the polymer was pretreated with hydroxylamine hydrochloride to obtain an amidoximated polymer. This material was additionally activated with acrylic chloride. Then HRP was immobilized on the cyanuric chloride-amidoxime acrylic polymer and was used as an efficient catalyst in the degradation of aromatic pollutants from wastewater. Similar research was presented by Almulaiky et al. [93]. However, in this case, the polymer was treated with hydrazine to introduce amidrazone groups, which act as nucleophilic sites suitable for cyanuric chloride activation and consequently improve the immobilization of the enzyme. Other investigations concern the enzymatic oxidative polymerization of phenol and bisphenol catalyzed by laccase enzyme immobilized on poly(acrylonitrile-co-styrene/pyrrole) nanofibers (AN-co-ST/Py) [94]. Interesting studies are reported by Liu et al. [95], who proposed a novel immobilization technology in which laccase was immobilized on a 3D bioprinted matrix hydrogel. The hydrogel contained different monomers: acrylamide (AM), hydroxyapatite (HA), and sodium alginate (SA) in various compositions. The prepared biocatalyst was used in the degradation of phenolic compounds, achieving a high yield.

In addition to synthesized polymers, biopolymers are also useful materials for constructing biocatalytic systems to treat phenolic pollutants. For example, hybrids based on polyamide/chitosan [96] or polyvinyl alcohol/chitosan [97] were used to immobilize laccase and chloroperoxidase, respectively. The proposed matrix was characterized by a high specific surface area, numerous binding sites, and good mechanical properties. This facilitated the immobilization of laccase on its surface, which allowed repeated application in the degradation of bisphenol and its derivatives. Chitosan chelated with $\mathrm{Cu}$ ions and supporting immobilized laccase was successfully used to remove phenol from an aqueous solution [98]. Bisphenol has also been successfully degraded by biocatalysts based on other polysaccharides, such as agarose. Before the immobilization of laccase, the surface of the saccharose was functionalized with monoaminoethyl- $N$ aminoethyl (MANAE) [99]. Similar studies were reported by Brungari et al. [100], who used a different kind of laccase. In both cases, the proposed biocatalytic systems displayed high enzymatic and biodegradation activity.

In addition to studies on traditional materials, recent research by $\mathrm{Zu}$ et al. is worth mentioning [101]. A Y-type zeolite was employed as a matrix for the laccase. Zeolites are characterized by wide availability, low price, and high thermal and acidic stability. Furthermore, their surfaces can be modified to improve their mesoporous structure. These properties enable zeolites to be used as supports for biomolecules. $\mathrm{Zu}$ et al. prepared sodium zeolite (NaY) and its modified desilicated (DSY) and dealuminated (DAY) forms. The modification led to significant improvement in immobilization performance and enabled the highly efficient biodegradation of bisphenol S and other phenolic compounds.

Polycyclic aromatic hydrocarbons (PAHs) have also been degraded using immobilized enzymes. As with organic dyes, pharmaceuticals and phenol compounds, PAHs are another significant group of environmental pollutants. PAHs have two or more fused benzene rings originating from natural or anthropogenic sources. They have harmful biological, toxic, mutagenic, and carcinogenic effects on the environment [102, 103]. For example, Bautista et al. immobilized laccase on amino-functionalized SBA 15 (a silica material) [104] and used it to remove naphthalene, phenanthrene, and anthracene from wastewater. The designed biocatalyst exhibited high incorporation yields of laccase and excellent biodegradation of various PAHs. Nonionic surfactant-modified clay with immobilized fungal laccase has also been reported as effective in removing PAH from groundwater. Naphthalene and phenanthrene were successfully biodegraded in the presence of this biocatalytic system [105]. The bioconversion of polycyclic aromatic hydrocarbons was also achieved by Apriceno et al. [106], who reported the covalent immobilization of laccase on glutaraldehyde-activated chitosan. Anthracene was efficiently removed by the obtained immobilized laccase with a high catalytic yield. Interesting research was reported by Chen et al. [107], who applied laccase to the surface of calciummodified chitosan-alginate (CA-Ca-SBE). Their results showed that the immobilized laccase was a promising biocatalyst for application in wastewater treatment due to its high performance in the degradation of phenanthrene in water.

In summary, the high degradation efficiency of phenol compounds and polycyclic aromatic hydrocarbons can be achieved using biocatalysts based on functionalized materials 


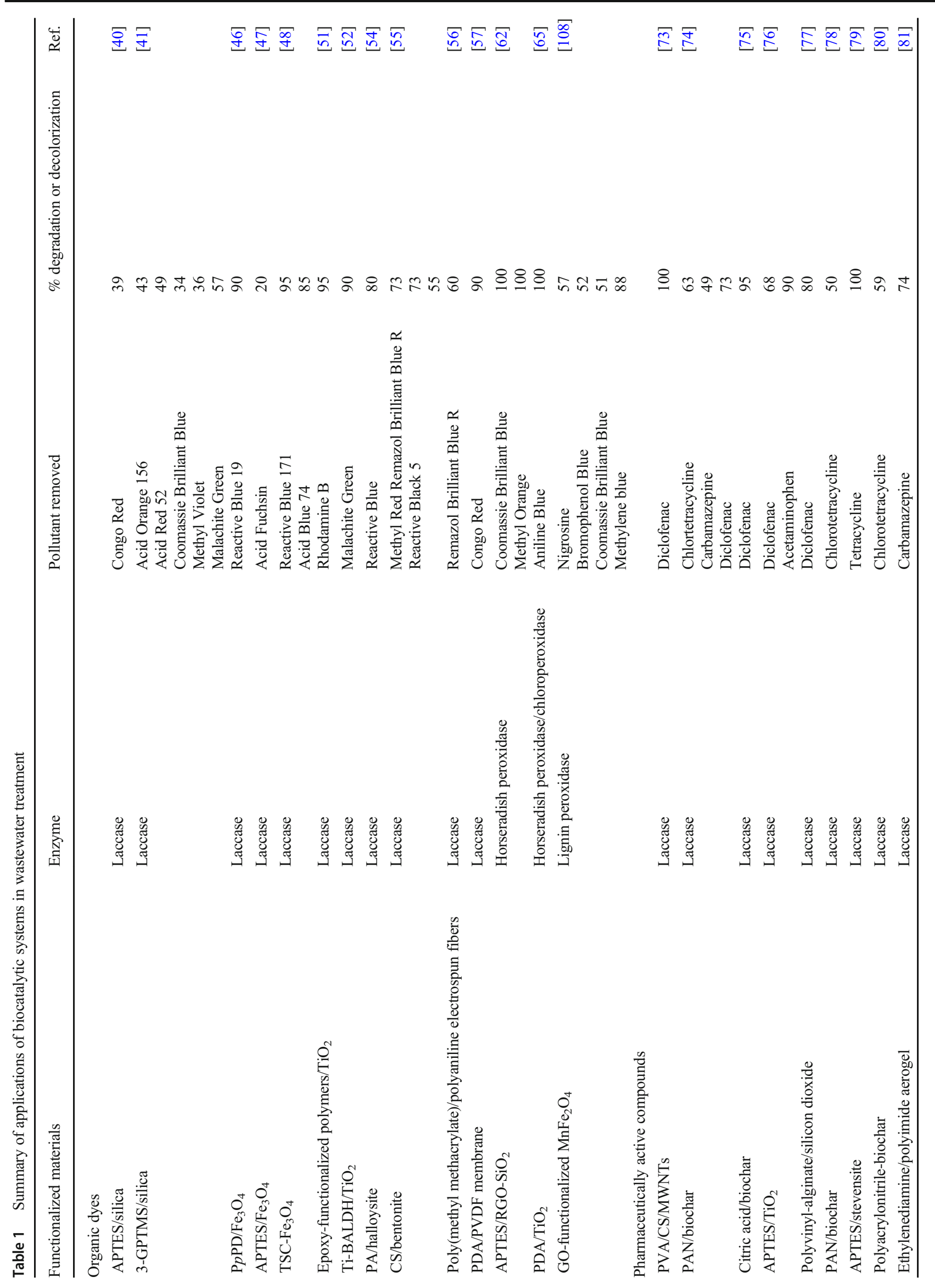




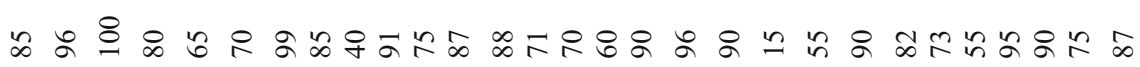

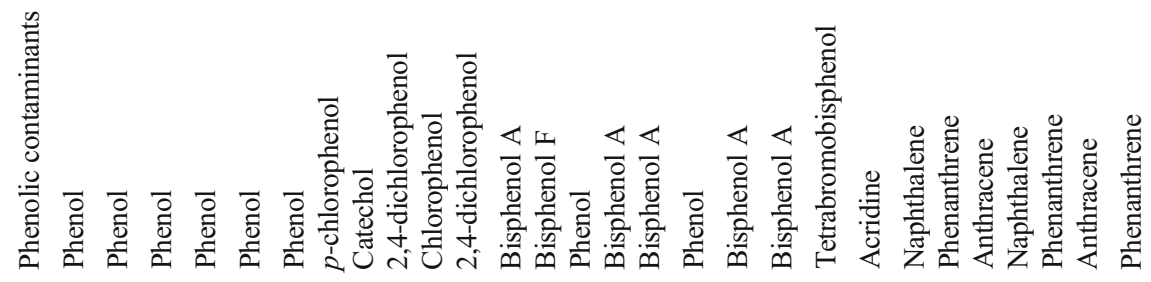

$\frac{\mathscr{m}}{\overparen{m}}$

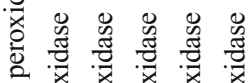

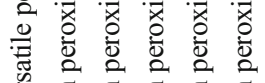

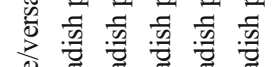

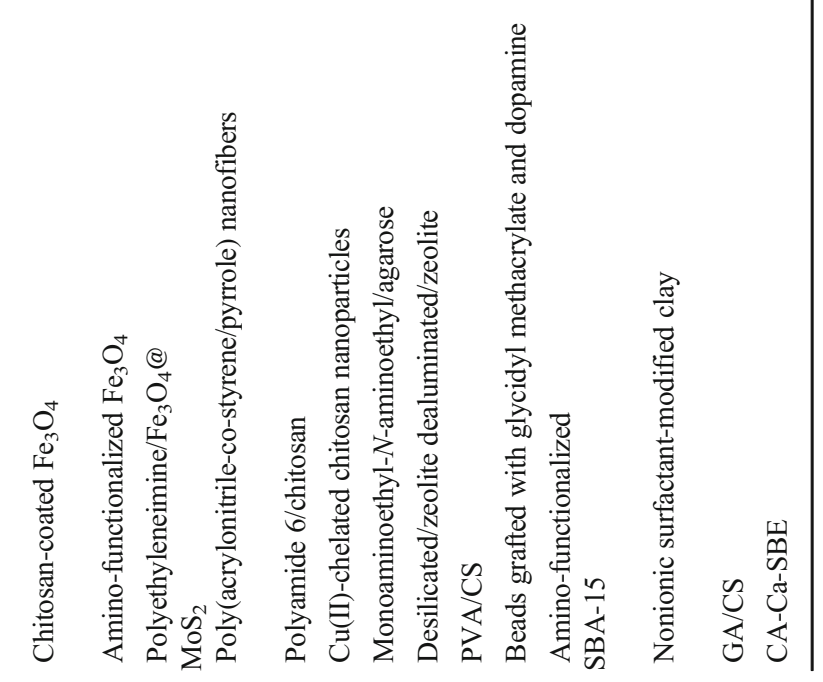


and enzymes. The support matrices considered protect the enzyme from the toxic effects of the pollutants and increase the effectiveness of their removal. The utilization of catalytic systems based on enzymes and functionalized materials ensures the rapid, easy, and low-cost degradation of phenolic compounds in wastewater.

The most common functionalized materials employed for enzymatic immobilization and their performance in removing organic dyes, pharmaceuticals, phenolic compounds, and polyacrylic aromatic hydrocarbons from wastewaters are summarized in Table 1.

\section{Conclusions}

This review has identified and presented information concerning different biocatalytic systems based on functionalized materials and enzyme immobilization. It aimed to review the applications of such biocatalytic systems for removing chemical pollutants (e.g., organic dyes, pharmaceuticals, phenol compounds, and polycyclic aromatic hydrocarbons) from wastewater. Materials in organic, inorganic, hybrid, and composite forms can be functionalized to increase their affinity to enzymes. In general, using the materials considered here, the immobilized enzymes exhibit high performance in the degradation of pollutants. In most cases, the immobilized enzymes are oxidoreductases, such as laccase and peroxidase. A further search for new enzymes and materials is recommended and is expected to improve the range and practicality of immobilized enzymes for wastewater treatment. This review also demonstrated that immobilized enzymes effectively contribute to the removal of pollutants from aqueous solutions (primarily organics, dyes, pharmaceuticals, and phenolic compounds). This work is expected to be useful for further developing new materials for enzyme immobilization with improved stability and effectiveness in the removal of water pollutants. Additionally, the information from this review may have practical significance in the selection of materials and immobilization methods, and the identification of suitable pollutants for treatment.

\footnotetext{
Abbreviations 3-GPTMS, 3-glycidyloxypropylotrimethoxysilane; ANco-ST/Py, Poly(acrylonitrile-co-styrene/pyrrole) nanofibers; AM, Acrylamide; APTES, Aminopropyltriethoxysilane; CA-Ca-SBE, Calcium-modified chitosan-alginate; CBZ, Carbamazepine; CS, Chitosan; CPO, Chloroperoxidase; DAY, Dealuminated zeolite; DSY, Desilicated zeolite; GA, Glutaraldehyde; GO, Graphene oxide; HA, Hydroxyapatite; HRP, Horseradish peroxidase; Lac, Laccase; LC-MS, Liquid chromatography-mass spectrometry; MANAE, Monoaminoethyl- $N$-aminoethyl; MSMS, Multifunctionalized magnetic silica microspheres; MWNTs, Multi-walled carbon nanotubes; NaY, Sodium zeolite; PAHs, Polycyclic aromatic hydrocarbons; PAN, Polyacrylonitrile; PDA, Polydopamine; P $p$ PD, Poly $(p-$ phenylenediamine); PVA, Polyvinyl alcohol; PVDF, Poly(vinylidene fluoride); RGO, Reduced graphene oxide; SA, Sodium alginate; TC, Tetracycline; TCS, Thiolated chitosan; Ti-BALDH, Titanium(IV) bis(ammonium lactato)dihydroxide
}

Funding This research was funded by the National Science Centre Poland, under the program MINIATURA 4, grant number: 2020/04/X/ ST5/00318.

\section{Declarations}

Conflict of Interest The authors declare that they have no conflicts of interest.

Human and Animal Rights and Informed Consent This article does not contain any studies with human or animal subjects performed by any of the authors.

Open Access This article is licensed under a Creative Commons Attribution 4.0 International License, which permits use, sharing, adaptation, distribution and reproduction in any medium or format, as long as you give appropriate credit to the original author(s) and the source, provide a link to the Creative Commons licence, and indicate if changes were made. The images or other third party material in this article are included in the article's Creative Commons licence, unless indicated otherwise in a credit line to the material. If material is not included in the article's Creative Commons licence and your intended use is not permitted by statutory regulation or exceeds the permitted use, you will need to obtain permission directly from the copyright holder. To view a copy of this licence, visit http://creativecommons.org/licenses/by/4.0/.

\section{References}

Papers of particular interest, published recently, have been highlighted as:

- Of importance

•• Of major importance

1.• Liu J, Wei X, Yuan D, Ren J, Xue J. Recent advances in preparation and application of functionalized mesoporous materials. Recent Innov Chem Eng. 2019;12:239-47. https://doi.org/10. $2174 / 2405520412666190705125639$ This review provides an overview of the preparation of functional mesoporous materials with functional groups, metal doping, and acid modification.

2. Rath D, Rana S, Parida KM. Organic amine-functionalized silicabased mesoporous materials: an update of syntheses and catalytic applications. RSC Adv. 2014;4:57111-24. https://doi.org/10. 1039/c4ra08005j.

3. Li XS, Zhu GT, Luo YB, Yuan BF, Feng YQ. Synthesis and applications of functionalized magnetic materials in sample preparation. Trends Analyt Chem. 2013;45:233-47. https://doi.org/10. 1016/j.trac.2012.10.015.

4. Yadav R, Baskaran T, Kaiprathu A, Ahmed M, Bhosale SV, Joseph S, et al. Recent advances in the preparation and applications of organofunctionalized porous materials. Chem Asian J. 2020;15:2588-621. https://doi.org/10.1002/asia.202000651.

5. Gargiulo N, Pepe F, Caputo D. $\mathrm{CO}_{2}$ adsorption by functionalized nanoporous materials: a review. J Nanosci Nanotechnol. 2014;14: 1811-22. https://doi.org/10.1166/jnn.2014.8893.

6. Jiao J, Cao J, Xia Y, Zhao L. Improvement of adsorbent materials for $\mathrm{CO}_{2}$ capture by amine functionalized mesoporous silica with worm-hole framework structure. Chem Eng J. 2016;15:9-16. https://doi.org/10.1016/j.cej.2016.07.041. 
7. Boudrant J, Woodley JM, Fernandez-Lafuente R. Parameters necessary to define an immobilized enzyme preparation. Process Biochem. 2020;90:66-80. https://doi.org/10.1016/j.procbio.2019. 11.026 In this article, reasons for the loss of activity during immobilization are discussed, suitable diagnostic tests to elucidate the precise cause are highlighted, and methods to restore activity are proposed.

8. Hassan ME, Yang Q, Xiao Z, Liu L, Wang N, Cui X, et al. Impact of immobilization technology in industrial and pharmaceutical applications. 3. Biotech. 2019;9:440-56. https://doi.org/10.1007/ s13205-019-1969-0.

9. Sheldon RA, Woodley JM. Role of biocatalysis in sustainable chemistry. Chem Rev. 2018;118:801-38. https://doi.org/10. 1021/acs.chemrev.7b00203.

10. Mateo C, Palomo JM, Fernandez-Lorente G, Guisan JM, Fernandez-Lafuente R. Improvement of enzyme activity, stability and selectivity via immobilization techniques. Enzyme Microb Technol. 2007;40:1451-63. https://doi.org/10.1016/j.enzmictec. 2007.01.018.

11. Garcia-Galan C, Berenguer-Murcia A, Fernandez-Lafuente R, Rodrigues RC. Potential of different enzyme immobilization strategies to improve enzyme performance. Adv Synth Catal. 2011;353:2885-904. https://doi.org/10.1002/adsc.201100534.

12. Zdarta J, Meyer AS, Jesionowski T, Pinelo M. A general overview of support materials for enzyme immobilization: characteristics, properties, practical utility. Catalysts. 2018;8:92-119. https://doi. org/10.3390/catal8020092.

13. Bilal M, Iqbal HMN. Naturally-derived biopolymers: potential platforms for enzyme immobilization. Int J Biol Macromol. 2019;130:462-82. https://doi.org/10.1016/j.ijbiomac.2019.02. 152.

14. Bilal M, IIgbal HMN. Armoring bio-catalysis via structural and functional coordination between nanostructured materials and lipases for tailored applications. Int J Biol Macromol. 2021;166: 818-38. https://doi.org/10.1016/j.ijbiomac.2020.10.239.

15. Zucca P, Sanjust E. Inorganic materials as supports for covalent enzyme immobilization: methods and mechanisms. Molecules. 2014;19:14139-94. https://doi.org/10.3390/ molecules 190914139 .

16. Barbosa O, Torres R, Ortiz C, Berenguer-Murcia A, Rodrigues RC, Fernandez-Lafuente R. Heterofunctional supports in enzyme immobilization: from traditional immobilization protocols to opportunities in tuning enzyme properties. Biomacromolecules. 2013;14:2433-62. https://doi.org/10.1021/bm400762h.

17. Liu DM, Dong C. Recent advances in nano-carrier immobilized enzymes and their applications. Process Biochem. 2020;92:464 75. https://doi.org/10.1016/j.procbio.2020.02.005.

18. Bilal M, Iqbal HM. Chemical, physical, and biological coordination: an interplay between materials and enzymes as potential platforms for immobilization. Coord Chem Rev. 2019;388:1-23. https://doi.org/10.1016/j.ccr.2019.02.024.

19. Deska M, Konczak B. Immobilized fungal laccase as "green catalyst" for the decolourization process - state of the art. Process Biochem. 2019;84:112-23. https://doi.org/10.1016/j.procbio. 2019.05.024.

20. Datta S, Veena R, Samuel MS, Selvarajan E. Immobilization of laccases and applications for the detection and remediation of pollutants: a review. Enviro Chem Lett. 2021;19:521-38. https://doi. org/10.1007/s10311-020-01081-y This work discusses the practical application of immobilized laccase in pollutant remediation.

21. Zhou W, Zhang W, Cai Y. Laccase immobilization for water purification: a comprehensive review. Chem Eng J. 2021;403: 126272-87. https://doi.org/10.1016/j.cej.2020.126272.

22. Bilal M, Barcelo D, Iqbal HMN. Nanostructured materials for harnessing the power of horseradish peroxidase for tailored environmental applications. Sci Total Environ. 2020;749: 142360-78. https://doi.org/10.1016/j.scitotenv.2020.142360.

23. Husain Q. Immobilized peroxidase catalyzed decolorization and degradation of industrially important dyes from polluted water. In: Husain Q, Ullah MF, editors. Biocatalysis. Enzymatic basics and applications. Switzerland AG: Springer Nature; 2019.

24. Zhang $\mathrm{C}$, Cai $\mathrm{X}$. Immobilization of horseradish peroxidase on $\mathrm{Fe}_{3} \mathrm{O}_{4} /$ nanotubes composites for biocatalysis degradation of phenol. Compos Interfaces. 2019;26:379-96. https://doi.org/10.1080/ 09276440.2018 .1504265$.

25. Wong JKH, Tana HK, Lau SY, Yap PS, Danquah MK. Potential and challenges of enzyme incorporated nanotechnology in dye wastewater treatment: a review. J Environ Chem Eng. 2019;7: 103261-78. https://doi.org/10.1016/j.jece.2019.103261.

26. Zdarta J, Meyer AS, Jesionowski T, Pinelo M. Developments in support materials for immobilization of oxidoreductases: a comprehensive review. Adv Colloid Interface Sci. 2018;258:1-20. https://doi.org/10.1016/j.cis.2018.07.004.

27. Naghdi M, Taheran M, Brar SK, Kermanshahi-pour A, Verma M, Surampalli RY. Removal of pharmaceutical compounds in water and wastewater using fungal oxidoreductase enzymes. Environ Pollut. 2018;234:190-213. https://doi.org/10.1016/j.envpol.2017. 11.060 .

28. Bilal M, Nguyen TA, Iqbal HM. Multifunctional carbon nanotubes and their derived nano-constructs for enzyme immobilization - a paradigm shift in biocatalyst design. Coord Chem Rev. 2020;422:213475. https://doi.org/10.1016/j.ccr.2020.213475.

29. Zhang S, Bilal M, Zdarta J, Cui J, Kumar A, Franco M, et al. Biopolymers and nanostructured materials to develop pectinasesbased immobilized nano-biocatalytic systems for biotechnological applications. Food Res Int. 2021;40:109979. https://doi.org/10. 1016/j.foodres.2020.109979.

30. Jun LY, Yon LS, Mubarak NM, Bing CH, Pan S, Danquah MK, et al. An overview of immobilized enzyme technologies for dye and phenolic removal from wastewater. J Environ Chem Eng. 2019;7:102961-5. https://doi.org/10.1016/j.jece.2019.102961.

31. Rasheed T, Bilal M, Nabeel F, Adeel M, Igbal HMN. Environmentally-related contaminants of high concern: potential sources and analytical modalities for detection, quantification, and treatment. Environ Int. 2019;122:52-66. https://doi.org/10. 1016/j.envint.2018.11.038.

32. Rai HS, Bhattacharyya MS, Singh J, Bansal TK, Vats P, Banerjee UC. Removal of dyes from the effluent of textile and dyestuff manufacturing industry: a review of emerging techniques with reference to biological treatment. Crit Rev Env Sci Technol. 2005;35:219-38. https://doi.org/10.1080/10643380590917932.

33. Parra-Saldivar R, Ramirez-Mendoza RA, Sharma A, Oza G, Zavala-Yoe R, Iqbal HM. Robust enzymes designing for efficient biocatalysis. In: Singh S, Pandey A, Singhania RR, Larroche C, Li Z, editors. Biomass, biofuels, biochemicals: Advances in enzyme catalysis and technologies. Elsevier; 2020.

34. Morsy SAGZ, Tajudin AA, Ali MSM, Shariff FM. Current development in decolorization of synthetic dyes by immobilized laccases. Front Microbiol. 2020;11:572309-17. https://doi.org/ 10.3389/fmicb.2020.572309.

35. Nguyen LN, Vu MT, Johir MAH, Pathak N, Zdarta J, Jesionowski $\mathrm{T}$, et al. A novel approach in crude enzyme laccase production and application in emerging contaminant bioremediation. Processes. 2020;8:648-60. https://doi.org/10.3390/pr8060648.

36. Bilal M, Ashraf SS, Cui J, Lou WY, Franco M, Mulla SI, et al. Harnessing the biocatalytic attributes and applied perspectives of nanoengineered laccases - a review. Int J Biol Macromol. 2021;166:352-73. https://doi.org/10.1016/j.ijbiomac.2020.10. 195.

37. Parra-Arroyo L, Parra-Saldivar R, Ramirez-Mendoza RA, Keshavarz T, Iqbal HM. Laccase-assisted cues: state-of-the-art 
analytical modalities for detection, quantification, and redefining "removal" of environmentally related contaminants of high concern. In: Schlosser D, editor. Laccases in bioremediation and waste valorisation. Cham: Springer; 2020.

38. Zhao M, Wang Y, Liu Z, Cui D, Bian X. Properties of immobilized laccase on mesostructured cellular foam silica and its use in dye decolorization. J Macromol Sci. 2011;48:447-53. https://doi.org/10.1080/10601325.2011.573330.

39. Jankowska K, Ciesielczyk F, Bachosz K, Zdarta J, Kaczorek E, Jesionowski $\mathrm{T}$. Laccase immobilized onto zirconia-silica hybrid doped with $\mathrm{Cu}^{2+}$ as an effective biocatalytic system for decolorization of dyes. Materials. 2019;12:1252-68. https://doi.org/10. 3390/ma12081252.

40. Lopez-Barbosa N, Florez SL, Cruz JC, Ornelas-Soto N, Osma JF. Congo red decolorization using textile filters and laccase-based nanocomposites in continuous flow bioreactors. Nanomaterials. 2020;10:1227-44. https://doi.org/10.3390/nano10061227.

41. Salami F, Habibi Z, Yousefi M, Mohammadi M. Covalent immobilization of laccase by one pot three component reaction and its application in the decolorization of textile dyes. Int $\mathrm{J}$ Biol Macromol. 2018;120:144-51. https://doi.org/10.1016/j.ijbiomac. 2018.08.077.

42. Li Z, Chen Z, Zhu Q, Song J, Li S, Liu X. Improved performance of immobilized laccase on $\mathrm{Fe}_{3} \mathrm{O}_{4} @ \mathrm{C}-\mathrm{Cu}^{2+}$ nanoparticles and its application for biodegradation of dyes. J Hazard Mater. 2020;399: 123088-95. https://doi.org/10.1016/j.jhazmat.2020.123088.

43. Wang J, Yu S, Feng F, Lu L. Simultaneous purification and immobilization of laccase on magnetic zeolitic imidazolate frameworks: recyclable biocatalysts with enhanced stability for dye decolorization. Biochem Eng J. 2019;150:107285-92. https://doi. org/10.1016/j.bej.2019.107285.

44. Ladole MR, Pokale PB, Patil SS, Belokar PG, Pandit AB. Laccase immobilized peroxidase mimicking magnetic metal organic frameworks for industrial dye degradation. Bioresour Technol. 2020;317:124035-44. https://doi.org/10.1016/j.biortech.2020. 124035 .

45. Sun T, Fu M, Xing J, Ge Z. Magnetic nanoparticles encapsulated laccase nanoflowers: evaluation of enzymatic activity and reusability for degradation of malachite green. Water Sci Technol. 2020;81:29-39. https://doi.org/10.2166/wst.2020.068.

46. Liu Y, Yan M, Geng Y, Huang J. Laccase immobilization on poly(p-phenylenediamine) $/ \mathrm{Fe}_{3} \mathrm{O}_{4}$ nanocomposite for Reactive Blue 19 dye removal. Appl Sci. 2016;6:232-48. https://doi.org/ 10.3390/app6080232.

47. Gao Z, Yi Y, Zhao J, Xia Y, Jiang M, Cao F, et al. Coimmobilization of laccase and TEMPO onto aminofunctionalized magnetic $\mathrm{Fe}_{3} \mathrm{O}_{4}$ nanoparticles and its application in acid fuchsin decolorization. Bioresour Bioprocess. 2018;5:2735. https://doi.org/10.1186/s40643-018-0215-7.

48. Ulu A, Birhanli E, Boran F, Koytepe S, Yesilada O, Ates B. Laccase-conjugated thiolated chitosan- $\mathrm{Fe}_{3} \mathrm{O}_{4}$ hybrid composite for biocatalytic degradation of organic dyes. Inter J Biol Macromol. 2020;150:871-84. https://doi.org/10.1016/j.ijbiomac. 2020.02.006.

49. Thao LTS, Dang TTT, Khanitchaidecha W, Channei D, Nakaruk A. Photocatalytic degradation of organic dye under UV-A irradiation using $\mathrm{TiO}_{2}$-vetiver multifunctional nanoparticles. Materials. 2017;10:122-34. https://doi.org/10.3390/ma10020122.

50. Khakshoor M, Makhdoumi A, Asoodeh A, Hosseindokht MR. Co-immobilized spore laccase/ $\mathrm{TiO}_{2}$ nanoparticles in the alginate beads enhance dye removal by two-step decolorization. Environ Sci Poll Res. 2021;28:6099-110. https://doi.org/10.1007/s11356020-10901-1.

51.• Wang D, Ding W, Zhou K, Guo S, Zhang Q, Haddleton DM. Coating titania nanoparticles with epoxy-containing catechol polymers via $\mathrm{Cu}(0)$-living radical polymerization as intelligent enzyme carriers. Biomacromolecules. 2018;19:2979-90. https:// doi.org/10.1021/acs.biomac. 8 b00544 This article reports on a facile strategy for the immobilization of metal oxide catalysts with enzymes, which constructs a novel bifunctional catalyst that may be promising for the "one-pot" degradation of different organic pollutants.

52. Zhang X, Wang M, Lin L, Xiao G, Tang Z, Zhu X. Synthesis of novel laccase-biotitania biocatalysts for malachite green decolorization. J Biosci Bioeng. 2018;126:69-77. https://doi.org/10.1016/ j.jbiosc.2018.01.021.

53. Chao C, Guan H, Zhang J, Liu Y, Zhao Y, Zhang B. Immobilization of laccase onto porous polyvinyl alcohol/ halloysite hybrid beads for dye removal. Water Sci Technol. 2018;77:809-18. https://doi.org/10.2166/wst.2017.594.

54. Gioia L, Ovsejevi K, Manta C, Miguez D, Menendez P. Biodegradation of acid dyes by an immobilized laccase: an ecotoxicological approach. Environ Sci Water Res Technol. 2018;4: 2125-35. https://doi.org/10.1039/c8ew00595h.

55. Mehandia S, Sharma SC, Arya SK. Immobilization of laccase on chitosan-clay composite beads to improve its catalytic efficiency to degrade industrial dyes. Mater Today Commun. 2020;25: 101513-23. https://doi.org/10.1016/j.mtcomm.2020.101513.

56. Jankowska K, Zdarta J, Grzywaczyk A, Kijenska-Gawronska E, Biadasz A, Jesionowski T. Electrospun poly(methyl methacrylate)/polyaniline fibres as a support for laccase immobilisation and use in dye decolourisation. Environ Res. 2020;184:10933242. https://doi.org/10.1016/j.envres.2020.109332.

57. Zhu Y, Qiu F, Rong J, Zhang T, Mao K, Yang D. Covalent laccase immobilization on the surface of poly(vinylidene fluoride) polymer membrane for enhanced biocatalytic removal of dyes pollutants from aqueous environment. Colloids Surf B. 2020;191: 111025-33. https://doi.org/10.1016/j.colsurfb.2020.111025.

58. Sekuljica NZ, Jovanovi JR, Tanaskovi SMJ, Ognjanovic ND, Gazikalovi IV, Jugovic ZDK, et al. Immobilization of horseradish peroxidase onto Purolite ${ }^{\circledR}$ A109 and its anthraquinone dye biodegradation and detoxification potential. Biotechnol Progress. 2020;36:2991-3000. https://doi.org/10.1002/btpr.2991.

59. Darwesh OM, Matter IA, Eida MF. Development of peroxidase enzyme immobilized magnetic nanoparticles for bioremediation of textile wastewater dye. J Environ Chem Eng. 2019;7:10280526. https://doi.org/10.1016/j.jece.2018.11.049.

60. Bilal M, Ashraf SS, Ferreira LFR, Cui J, Lou WY, Franco M, et al. Nanostructured materials as a host matrix to develop robust peroxidases-based nanobiocatalytic systems. Int J Biol Macromol. 2020;162:1906-23. https://doi.org/10.1016/j. ijbiomac.2020.08.122.

61. Sun H, Jin X, Jiang F, Zhang R. Immobilization of horseradish peroxidase on $\mathrm{ZnO}$ nanowires/macroporous $\mathrm{SiO}_{2}$ composites for the complete decolorization of anthraquinone dyes. Appl Biochem Biotechnol. 2018;65:220-9. https://doi.org/10.1002/bab.1559.

62. Vineh MB, Saboury AA, Poostchi AA, Ghasemi A. Biodegradation of phenol and dyes with horseradish peroxidase covalently immobilized on functionalized $\mathrm{RGO}-\mathrm{SiO}_{2}$ nanocomposite. Int J Biol Macromol. 2020;164:4403-14. https://doi.org/ 10.1016/j.ijbiomac.2020.09.045 This article describes an efficient, practical, and reliable biocatalytic system which can be regarded as eco-friendly and economical for extensive usage.

63. Jin $\mathrm{X}$, Li S, Long N, Zhang R. A robust and stable nanobiocatalyst by co-immobilization of chloroperoxidase and horseradish peroxidase for the decolorization of azo dyes. $\mathrm{J}$ Chem Technol Biotechnol. 2018;93:489-97. https://doi.org/10.1002/ jetb.5379.

64. Gao F, Guo Y, Fan X, Hu M, Li S, Zhai Q, et al. Enhancing the catalytic performance of chloroperoxidase by co-immobilization 
with glucose oxidase on magnetic graphene oxide. Biochem Eng J. 2019;143:101-9. https://doi.org/10.1016/j.bej.2018.12.013.

65. Cheng H, Hu M, Zhai Q, Li S, Jiang Y. Polydopamine tethered $\mathrm{CPO} / \mathrm{HRP}-\mathrm{TiO}_{2}$ nanocomposites with high biocatalytic activity, stability and reusability: enzyme-photo bifunctional synergistic catalysis in water treatment. Chem Eng J. 2018;347:703-10. https://doi.org/10.1016/j.cej.2018.04.083.

66.• Bilal M, Ashraf SS, Barcelo D, Iqbal HMN. Biocatalytic degradation/redefining "removal" fate of pharmaceutically active compounds and antibiotics in the aquatic environment. Sci Total Environ. 2019;691:1190-211. https://doi.org/10.1016/j.scitotenv. 2019.07.224 This review summarizes current literature on enzymes as biocatalytic systems, in free and immobilized forms, and their effective use in the degradation of various pharmaceutically active compounds present in water bodies.

67. Li X, Ji M, Nghiem LD, Zhao Y, Liu D, Yang Y, et al. A novel red mud adsorbent for phosphorus and diclofenac removal from wastewater. J Mol Liq. 2020;303:112286-98. https://doi.org/10. 1016/j.molliq.2019.112286.

68. Yusuf Y. The utilization of laccase-functionalized graphene oxide as an effective biodegradation of pharmaceutical industry waste: diclofenac and ibuprofen. Sys Rev Pharm. 2020;11:536-44. https://doi.org/10.5530/srp.2020.1.67.

69. Aguilar-Perez KM, Aviles-Castrillo JI, Ruiz-Pulido G. Nanosorbent materials for pharmaceutical-based wastewater effluents - an overview. Case Stud Chem Environ Eng. 2020;2:100055. https://doi.org/10.1016/j.cscee.2020.100028.

70. Alharbi SK, Nghiem LD, van de Merwe JP, Leusch FDL, Asif MB, Hai FI, et al. Degradation of diclofenac, trimethoprim, carbamazepine, and sulfamethoxazole by laccase from Trametes versicolor: transformation products and toxicity of treated effluent. Biocatal Biotrans. 2019;37:399-408. https://doi.org/10.1080/ 10242422.2019.1580268.

71. Zdarta J, Jankowska K, Wyszowska M, Kijeńska-Gawrońska E, Zgoła-Grześkowiak A, Pinelo M, et al. Robust biodegradation of naproxen and diclofenac by laccase immobilized using electrospun nanofibers with enhanced stability and reusability. Mater Sci Eng C. 2019;103:109789-99. https://doi.org/10.1016/ j.msec.2019.109789.

72. Primozic M, Kravanja G, Knez Z, Crnjac A, Leitgeb M. Immobilized laccase in the form of (magnetic) cross-linked enzyme aggregates for sustainable diclofenac (bio)degradation. J Clean Prod. 2020;275:124121-37. https://doi.org/10.1016/j. jclepro.2020.124121.

73. Xu R, Tang R, Zhou Q, Li F, Zhang B. Enhancement of catalytic activity of immobilized laccase for diclofenac biodegradation by carbon nanotubes. Chem Eng J. 2015;262:88-95. https://doi.org/ 10.1016/j.cej.2014.09.072.

74. Taheran M, Naghdi M, Brar SK, Knystautas EJ, Verma M, Surampalli RY. Covalent immobilization of laccase onto nanofibrous membrane for degradation of pharmaceutical residues in water. ACS Sustainable Chem Eng. 2017;5:10430-8. https://doi.org/10.1021/acssuschemeng.7b02465.

75. Lonappan L, Liu Y, Rouissi T, Pourcel F, Brar SK, Verma M, et al. Covalent immobilization of laccase on citric acid functionalized micro-biochars derived from different feedstock and removal of diclofenac. Chem Eng J. 2018;351:985-94. https://doi.org/ 10.1016/j.cej.2018.06.157.

76. Garcia-Morales R, Garcia-Garcia A, Orona-Navara C, Osma JF, Nigama KDP, Ornelas-Soto N. Biotransformation of emerging pollutants in groundwater by laccase from $P$. sanguineus CS43 immobilized onto titania nanoparticles. J Environ Chem Eng. 2018;6:710-7. https://doi.org/10.1016/j.jece.2017.12.006.

77. Neelkant KS, Shankar K, Jayalakshmi SK, Sreeramulu K. Purification, biochemical characterization, and facile immobilization of laccase from Sphingobacterium ksn-11 and its application in transformation of diclofenac. Appl Biochem Biotechnol. 2020;192:831-44. https://doi.org/10.1007/s12010-020-03371-1.

78. Taheran M, Naghdi M, Brar SK, Knystautas EJ, Verma M, Surampalli RY. Degradation of chlortetracycline using immobilized laccase on polyacrylonitrile-biochar composite nanofibrous membrane. Sci Total Environ. 2017;605-606:31521. https://doi.org/10.1016/j.scitotenv.2017.06.185.

79.• Garcia-Delgado C, Eymar E, Camacho-Arevalo R, Petruccioli M, Crognalec S, D'Annibale A. Degradation of tetracyclines and sulfonamides by stevensite- and biochar-immobilized laccase systems and impact on residual antibiotic activity. J Chem Technol Biotechnol. 2018;93:3394-409. https://doi.org/10.1002/jctb.5697 This article shows the role of functionalized biochar and mineral in the preparation of biocatalysts and their application in the degradation of pharmaceutical compounds.

80. Taheran M, Naghdi M, Brar SK, Kermanshahi-pour A, Verma M, Surampalli RY. Immobilized laccase on oxygen functionalized nanobiochars through mineral acids treatment for removal of carbamazepine. Sci Total Environ. 2017;584-585:393-401. https:// doi.org/10.1016/j.scitotenv.2017.01.021.

81. Simon-Herrero C, Naghdi M, Taheran M, Brar SK, Romero A, Valverde JL, et al. Immobilized laccase on polyimide aerogels for removal of carbamazepine. J Hazard Mater. 2019;376:83-90. https://doi.org/10.1016/j.jhazmat.2019.05.032.

82. Qiu X, Wang Y, Xue Y, Li W, Hu Y. Laccase immobilized on magnetic nanoparticles modified by amino-functionalized ionic liquid via dialdehyde starch for phenolic compounds biodegradation. Chem Eng J. 2020;391:123564. https://doi.org/10.1016/j.cej. 2019.123564.

83. Asif MB, Hai FI, Dhar BR, Ngo HH, Guo W, Jegatheesan V, et al. Impact of simultaneous retention of micropollutants and laccase on micropollutant degradation in enzymatic membrane bioreactor. Bioresour Technol. 2018;267:473-80. https://doi.org/10.1016/j. biortech.2018.07.066.

84. Vishnu D, Neeraj G, Swaroopini R, Shobana R, Kumar VV, Cabana H. Synergetic integration of laccase and versatile peroxidase with magnetic silica microspheres towards remediation of biorefinery wastewater. Environ Sci Pollut Res. 2017;24:179938009. https://doi.org/10.1007/s11356-017-9318-5.

85. Mohammadi M, As'habi MA, Salehi P, Yousefi M, Nazari M, Brask J. Immobilization of laccase on epoxy-functionalized silica and its application in biodegradation of phenolic compounds. Inter J Biol Macromol. 2018;109:443-7. https://doi.org/10.1016/j. ijbiomac.2017.12.102.

86. Vineh MB, Saboury AA, Poostchi AA. Biodegradation of phenol and dyes with horseradish peroxidase covalently immobilized on functionalized $\mathrm{RGO}-\mathrm{SiO}_{2}$ nanocomposite. Inter J Biol Macromol. 2020;164:4403-14. https://doi.org/10.1016/j.ijbiomac.2020.09. 045.

87. Vineh MB, Saboury AA, Poostchi AA, Mamani L. Physical adsorption of horseradish peroxidase on reduced graphene oxide nanosheets functionalized by amine: a good system for biodegradation of high phenol concentration in wastewater. Inter J Environ Res. 2018;12:45-57. https://doi.org/10.1007/s41742-018-0067-1 This article presents the role of an amino-functionalized oxide system in the production of a biocatalytic system and its use in phenol degradation.

88. Zhang K, Yang W, Liu Y, Zhang K, Chen Y, Yin X. Laccase immobilized on chitosan-coated $\mathrm{Fe}_{3} \mathrm{O}_{4}$ nanoparticles as reusable biocatalyst for degradation of chlorophenol. J Mol Struct. 2020;1220:128769-76. https://doi.org/10.1016/j.molstruc.2020. 128769.

89. Wu E, Li Y, Huang Q, Yang Z, Wei A, Hu Q. Laccase immobilization on amino-functionalized magnetic metal organic framework for phenolic compound removal. Chemosphere. 2019;233: 327-35. https://doi.org/10.1016/j.chemosphere.2019.05.150. 
90. Ran F, Zou Y, Xu Y, Liu X, Zhang H. Fe $3 \mathrm{O}_{4} @ \mathrm{MoS}_{2} @$ PEI-facilitated enzyme tethering for efficient removal of persistent organic pollutants in water. Chem Eng J. 2019;375:121947-54. https:// doi.org/10.1016/j.cej.2019.121947.

91. Li A, Yang X, Yu B, Cai X. Immobilization of horseradish peroxidase on polyglycerol-functionalized magnetic $\mathrm{Fe}_{3} \mathrm{O}_{4} /$ nanodiamond nanocomposites and its application in phenol biodegradation. Res Chem Intermed. 2020;46:101-18. https://doi. org/10.1007/s11164-019-03937-7.

92. Mohamed SA, Al-Ghamdi SS, El-Shishtawy RM. Immobilization of horseradish peroxidase on amidoximated acrylic polymer activated by cyanuric chloride. Inter J Biol Macromol. 2016;91:66370. https://doi.org/10.1016/j.ijbiomac.2016.06.002.

93. Almulaiky YQ, El-Shishtawy RM, Aldhahri M, Mohamed SA, Afifi M, Abdulaal WH, et al. Amidrazone modified acrylic fabric activated with cyanuric chloride: a novel and efficient support for horseradish peroxidase immobilization and phenol removal. Inter J Biol Macromol. 2019;140:949-58. https://doi.org/10.1016/j. ijbiomac.2019.08.179.

94. El-Aassar MR, Alsohaimi IH, Ali ASM, Elzain AA. Removal of phenol and bisphenol A by immobilized laccase on poly(acrylonitrile-co-styrene/pyrrole) nanofibers. Sep Sci Technol. 2020;55: 2670-8. https://doi.org/10.1080/01496395.2019.1648511.

95. Liu J, Shen X, Zheng Z, Li M, Zhu X, Cao H, et al. Immobilization of laccase by $3 \mathrm{D}$ bioprinting and its application in the biodegradation of phenolic compounds. Inter J Biol Macromol. 2020;164: 518-25. https://doi.org/10.1016/j.ijbiomac.2020.07.144.

96. Maryskova M, Ardao I, Garcia-Gonzalez CA, Martinova L, Rotkova J, Sevcu A. Polyamide 6/chitosan nanofibers as support for the immobilization of Trametes versicolor laccase for the elimination of endocrine disrupting chemicals. Enzyme Microb Technol. 2016;89:31-8. https://doi.org/10.1016/j.enzmictec. 2016.03.001.

97. Garcia-Zamora JL, Santacruz-Vazquez V, Valera-Perez MA, Moreira MT, Cardenas-Chavez DL, Tapia-Salazar M, et al. Oxidation of flame retardant tetrabromobisphenol A by a biocatalytic nanofiber of chloroperoxidase. Int J Environ Res Public Health. 2019;16:4917-32. https://doi.org/10.3390/ ijerph16244917.

98. Alver E, Metin AU. Chitosan based metal-chelated copolymer nanoparticles: laccase immobilization and phenol degradation studies. Int Biodeter Biodegr. 2017;125:235-42. https://doi.org/ 10.1016/j.ibiod.2017.07.012.

99. Brugnari T, Pereira MG, Bubna GA, de Freitas EN, Contato AG, Correa RCG, et al. A highly reusable MANAE-agaroseimmobilized Pleurotus ostreatus laccase for degradation of bisphenol A. Sci Total Environ. 2018;634:1346-51. https://doi. org/10.1016/j.scitotenv.2018.04.051.
100. Brugnari T, Contato AG, Pereira MG, de Freitasa EN, Bubna GA, Aranha GM, et al. Characterisation of free and immobilised laccases from Ganoderma lucidum: application on bisphenol a degradation. Biocatal Biotransform. 2020;39:71-80. https://doi. org/10.1080/10242422.2020.1792448.

101. Taghizadeh T, Talebian-Kiakalaieh A, Jahandar H, Amin M, Tarighic S, Faramarzi MA. Biodegradation of bisphenol A by the immobilized laccase on some synthesized and modified forms of zeolite Y. J Hazard Mater. 2020;386:121950-61. https://doi. org/10.1016/j.jhazmat.2019.121950.

102. Haritash AK, Kaushik CP. Biodegradation aspects of polycyclic aromatic hydrocarbons (PAHs): a review. J Hazard Mater. 2009;169:1-15. https://doi.org/10.1016/j.jhazmat.2009.03.137.

103. Xue P, Liu X, Gu Y, Zhang W, Ma L, Li R. Laccase-mediator system assembling co-immobilized onto functionalized calcium alginate beads and its high-efficiency catalytic degradation for acridine. Colloid Surf B. 2020;196:111348-55. https://doi.org/ 10.1016/j.colsurfb.2020.111348.

104. Bautista LF, Morales G, Sanz R. Biodegradation of polycyclic aromatic hydrocarbons (PAHs) by laccase from Trametes versicolor covalently immobilized on amino-functionalized SBA-15. Chemosphere. 2015;136:273-80. https://doi.org/10. 1016/j.chemosphere.2015.05.071.

105. Chang YT, Lee JF, Liu KH, Liao YF, Yang V. Immobilization of fungal laccase onto a nonionic surfactant-modified clay material: application to PAH degradation. Environ Sci Pollut Res. 2016;23: 4024-35. https://doi.org/10.1007/s11356-015-4248-6.

106. Apriceno A, Bucci R, Girelli AM. Immobilization of laccase from Trametes versicolor on chitosan macrobeads for anthracene degradation. Anal Lett. 2017;50:2308-22. https://doi.org/10.1080/ 00032719.2017 .1282504$.

107. Chen X, Hu Z, Xie H, Ngo HH, Guo W, Zhang J. Enhanced biocatalysis of phenanthrene in aqueous phase by novel CA-CaSBE-laccase biocatalyst: performance and mechanism. Colloid Surf A Article. 2021;611:125884. https://doi.org/10.1016/j. colsurfa.2020.125884.

108. Kiran CH, Rathour RK, Bhatia RK, Rana DS, Bhatt AK, Thakur N. Fabrication of thermostable and reusable nanobiocatalyst for dye decolourization by immobilization of lignin peroxidase on graphene oxide functionalized $\mathrm{MnFe}_{2} \mathrm{O}_{4}$ superparamagnetic nanoparticles. Bioresour Technol. 2020;317:124020-31. https://doi. org/10.1016/j.biortech.2020.124020.

Publisher's Note Springer Nature remains neutral with regard to jurisdictional claims in published maps and institutional affiliations. 